\title{
Frontal sinus CSF leak: current management
}

\section{Objective}

There is little discussion in literatures about Frontal Sinus CSF Leak. The objective of this study was to present a review article about this disease.

Keywords: CSF leak, frontal sinus, frontal sinus fracture, anterior skull base fracture

\section{Introduction}

The history of frontal sinus surgery started when Wells removed a mucopyocele of the frontal Sinus in 1870. Many surgeons such Reidel-SchenkeandRohrich have used ablative or obliterative methods to treat the pathology of the frontal sinus. The osteoplastic flap procedure was developed byBergara and Itoiz In order to improve cosmetics and surgical exposure. Donald and Bernstein introduced Cranialization of the frontal sinus to treat frontal sinus fractures. The management of frontal sinus fractures and CSF leak has changed so

\author{
Volume 10 Issue 6 - 2018
}

Omar Ramadan

Independent Researcher, Kuwait

Correspondence: Omar Ramadan, Independent Researcher, Paterson NJ, Kuwait, Tel 0019735639283 ,

Email omarrem982@hotmail.com Received: September 07, 2016 | Published: November 26,
2018

much due newer instrumentation and techniques of nasal endoscopy. CSF leak of frontal sinus is a rare condition that should be managed carefully; Table 1 predicts the incidence of Frontal Sinus CSF Leak among other site of nasal CSF leak. ${ }^{1}$

Table I predict the incidence of Frontal Sinus CSF Leak

\begin{tabular}{|c|c|c|c|c|c|c|}
\hline & Number & Ethmoid & Sephenoid & $\begin{array}{l}\text { Sella and } \\
\text { clivus }\end{array}$ & $\begin{array}{l}\text { Frontal sinus } \\
\text { and recess }\end{array}$ & Success \\
\hline Lee et al. ${ }^{2}$ & 28 & 9 & 4 & 6 & 9 & $84 \%$ \\
\hline Nyguist et al. ${ }^{3}$ & 32 & $\begin{array}{l}9 \text { Cribriform plate } \\
7 \text { Fovea ethmoidalis } \\
2 \text { Combined fovea ethmoidalis/ } \\
\text { cribriform plate }\end{array}$ & 6 & $\begin{array}{l}4 \text { Sella } \\
4 \text { Clivus }\end{array}$ & I & $93.8 \%$ \\
\hline Wu et al. ${ }^{4}$ & 16 & $\begin{array}{l}3 \text { Cribriform roof } \\
4 \text { The nasal cavity top }\end{array}$ & 6 & & 3 & $100 \%$ \\
\hline Virk et al. ${ }^{5}$ & 54 & $\begin{array}{l}24 \text { Cribriform } \\
9 \text { Ethmoid }\end{array}$ & 14 & & 7 & $\begin{array}{l}93 \% \\
\text { Second } 100 \%\end{array}$ \\
\hline Martin et al. ${ }^{6}$ & 30 & $\begin{array}{l}\text { Cribriform plate }(76,6 \%) \text {. Followed by } \\
\text { the ethmoid roof }(23,4 \%)\end{array}$ & & & & $93 \%$ \\
\hline Bhatti et al. ${ }^{7}$ & 21 & $\begin{array}{l}10 \text { Cribriform plate } \\
2 \text { Ethmoid }\end{array}$ & 5 & & 4 & $80 \%$ \\
\hline
\end{tabular}

\section{Material and Method}

Literature review was conducted using PubMed (MEDLINE) for English articles, from January 2000 to May 2016. The following keywords were used: Frontal AND sinus AND CSF AND leeak: Frontal AND sinus AND cerberospinal AND leak: Frontal AND Sinus AND Fracture. Anterior AND skull AND Base AND Fracture Table 2.

\section{Results}

11 articles of frontal sinus CSF Leak have been reported in PubMed (MEDLINE) English articles for, 6 articles about Endoscopic Management, 2 articles about intracranial approach, one article about extra cranial approach using endoscopic via trephine, one article aboutcranialization, and one about combined endoscopic and extracranial approach. Trauma is the most common cause of Frontal Sinus CSf leak, Endoscopic management is the preferred method of treatment and works for most cases. Endoscopic approach is limited in superior and lateral defect of frontal sinus and those cases better to be treated by extracranial approach or combined Approach. Intracranial approach still used by Neurosurgeons for extensive anterior skull base fracture. Cranialisation was a common surgery to treat frontal sinus CSF leak, but now it is used for extensive or communicated posterior table fracture with CSF leak. Endoscopic Management Failure of frontal sinus of CSF leak is higher than other sites. Success results varies from $75 \%-100 \%$. 


\section{Discussion}

CSF is produced by the choroid plexus, it provides mechanical and immunological protection for the brain, CSF leaks occur when there is a fistula due a rupture in the skull and the underling Dura causing CSF to leak through nose. Trauma is the most common cause of CSF leak and usually appears within the first week. $10 \%$ of patients CSF leak may complain of meningitis, and we should suspect CSF leak in any patient complains of recurrent meningitis. ${ }^{9}$

\section{Etiology of frontal sinus CSF leak}

a. Trauma: blunt trauma during a motor vehicle Accident is the most common cause of Fractures of the frontal sinus,.Frontal sinus fractures represent $5 \%-15 \%$ of maxillofacial traumas. The incidence of frontal sinus fracture is 9 per 100,000 dults per year. A third of frontal sinus fractures affect the anterior table alone; isolated fractures of the posterior table of frontal sinus are rare, and $20 \%$ of patients complain of Gross CSF rhinorrhea, it is always associated with orbital fractures.

b. Iatrogenic: Post Craniotomy or Post-FESS, defects tend to occur in sites of bony disruption during endoscopic sinus surgery or neurosurgery.

c. Congenital: skull base congenital defects and meningoceles or meningoencephalocles

d. Tumor.

e. Spontaneous CSF leak: Spontaneous frontal sinus CSF leaks tend to occur in anatomic sites of weakness that will release under increased hydrostatic pressure from elevated ICP, including the ethmoid roof or anterior cribriform plate adjacent to frontal recess; it has a lower rate of successful treatment 8 .

\section{Clinical exam}

i. Discover during screen exam in Head trauma patients.

ii. Discover during screen exam in post Fess and craniotomy patients.

iii. Suspected in recurrent meningitis patients, or patients with pneumocephale (complications). ${ }^{2}$

\section{Radiographic and laboratory exams}

1. Simple Skull Xray: not effective, But it may demonstrate fracture and pneumocephalus.

2. High Resolution CT Scan; is a useful screening examination for the initial workup of CSF rhinorrhea, it demonstrate the site of fracture and associated meningocele,

3. Computerized isternography and radionuclide cisternography should be used if MR imaging is contraindicated or if a clinically and biologically proven CSF fistulae is not visualized by CT or MR imaging.

4. Laboratory Exam: screen nasal clear secretion for Beta-2 transferrin is a is almost exclusively Found in the CSF, Beta-2 transferrin is not found in blood, nasal secretion or tears.

5. In the presence of a skull base fracture on CT and a clinical CSF leak, there is no need for a further confirmatory test in cases where a confirmatory test is needed; the beta- 2 transferrin assay is the test of choice because of its high sensitivity and specificity

6. Intrathecal fluorescein is usually used to confirm and localize the
CSF leak fistula during the operation. The recommended dose is $0.1 \mathrm{~mL}$ of $10 \%$ intravenous fluorescein diluted in $10 \mathrm{~mL}$ of the patient's own CSF then it is infused slowly over 30 minutes. A yellow fluid leaking is visualized from the site of CSF leak in the nose. ${ }^{17}$

Management of frontal CSF Leak starts with Conservative Treatment for 7days including Avoid Coughing, Straining, Sneezing, Nose blowing and vomiting. Bed rest and 30 degree head elevation degrees. Prophylactic Antibiotics are controversial. If Conservative management fails we can use Lumbar Drains for one week. Surgical Treatment is the last choice and includes Transnasal Endoscopic approach, extracranial approach, Transcranial approach and Cranialization. $^{0}$

\section{Frontal CSF leak Repair method is determined by:}

1) Location Of defect: defects located at Superior and lateral parts of posterior frontal defects are difficult to access with current nasal endoopisc methods. These cases and larger or complex defects are better to be managed by a frontal sinus drill-out, a combined endoscopic and intracranial approach, or an external approach.

2) Size of defect: The size of the defect also has a great role in surgical planning for the required graft type.smaller defects can be managed by an overlay grafts, and larger $(>4 \mathrm{~mm})$ sites need an underlay graft or multilayer closure with both underlay and overlay grafts. Some situations need a stronger reconstruction (very large defects or elevated ICP) using underlay bony grafts and soft overlay grafts with bony countersinking techniques.

3) Degree of Dural involvement:

4) Presence of elevated intracranial pressure (ICP)

5) Possibility of meningoencephaloceleprotrusion. ${ }^{8}$

\section{Surgical approach \\ Endoscopic approach}

was first described by Wigand in 1981 was first described Endoscopic closure of CSF leaks, and until now, it is the preferred method of CSF leak closure because of its high success rate (90-97\%), Endoscopic approach to frontal sinus is difficult due to the Unique anatomy of frontal sinus, But Using angled 70 degree endoscopes and frontal sinus giraffe instruments make the endoscopic approach more compatible. But reaching more superior and lateral area of frontal sinus is still difficult. Frontal recess stenosis is a possible complication of Endoscopic Frontal Sinus. Maintaining the functioning, and drainage of the sinus is preferable to sinus obliteration as it allows to evaluate the mucocele formation endoscopilly, but in more advanced frontal sinus defects this can be difficult to achieve. ${ }^{8}$

\section{Defect site preparation}

We should remove a rim of mucosa around the defect edge to prevent mucus production under the graft from detaching it; we also should remove mucosa from sinus portions that will be obliterated or could be influenced by outflow obstruction. After that the graft can be positioned. The grafts should lie smoothly against the defect and must be put carefully so the mucosal surface facing toward the nasal cavity or sinus to prevent mucocele or other intracranial complications. After that a multiple kind of sealants and packing are used tofix graft during its initial healing and adherence to the defect site, including Dura Seal, Gel Film (Tisseel, Gelfoam, and Surgicel) (Table 3) (Table 4). ${ }^{8}$ 
Table 3 Type of Grafts

Mucosal soft graft

Nonmucosal soft graft materials
I. Local mucosal flaps (turbinate rotational flap, septalmucoperichondrial flap)

2. Free mucosal flaps, which benefit from a vascular supply in pedicled local flaps cartilage, bone, Medporand hydroxyapatite cementgrafts.

Table 4 Factors influence graft Success

Risk factors for graft failure
$\begin{aligned} \text { i. } & \text { High body mass index, } \\ \text { ii. } & \text { Large defect size, } \\ \text { iii. } & \text { Spontaneous CSF leak etiology (implying potentially } \\ & \text { elevated ICP) } \\ \text { iv. } & \text { Lateral sphenoid defect location. }\end{aligned}$

\section{Decrease graft failure}

i. Using appropriate graft types

ii. With multilayer closures

iii. 2firm graft underlays orcountersinking

iv. Decrease elevated ICP (lumbar drains, acetazolamide)

v. Ensure that grafts lie smoothly against the defect and cover a sufficient margin beyond the defect edge by

vi. At least $5 \mathrm{~mm}$
Postoperative recommendations: are bed rest, 30 degree head elevation, using stool softeners, antiemetics, blood pressure control, and the patient should advise to stop sneezing, nose blowing, coughing, and Valsalva maneuvers. Postoperative follow-up with CT scanning is Important. ${ }^{9}$

Transcranial Approach: Dandy successed in repairing CSF fistula of frontal sinus using bifrontal craniotomy for accessandlata graft for repair in 1926 . Failure rate is around $27 \%$. Table $4 .{ }^{15}$
Extra cranial approach: He used a naso-orbital incision Dohlman was the firstdescribed The first extracranial approach to repair a CSF leak, Success rates with this approach range from $86 \%$ to $97 \%$, The benefits of this approach include improved success rates with decreased morbidity and mortality (Table 4$).{ }^{1}$

Cranialization of the frontal sinus: Was considered the treatment of choice for frontal Sinus CSF, it includes the removal of posterior wall of frontal sinu sand and all mucosa (Table 5). ${ }^{16}$

\section{Table 5}

\author{
Extra cranial trans-cranial sub-frontal repair CSf- Leak preserving Frontal \\ Sinus \\ Induction: Moderately depressed and comminuted fractures of the posterior wall \\ with displacement of bony fragments greater than one wall thickness. \\ Surgery: \\ Bicoronal scalp incision \\ - Bifrontal craniotomy. \\ - Brain is retracted and the site of the defect is identified \\ -Removal of disrupted, loose or folded Mucosa \\ -Reposition of loose bony fragments of the posterior wall to reestablish normal sinus \\ anatomy. \\ -Exploration of The nasofrontal duct \\ -The dura repair by running suture or using, \\ -We can place Free periosteal flaps along the floor of the frontal fossa When secure, \\ water-tight closure was difficult. \\ Complication: Failure to stop leakage, Anosmia, Meningitis, Wound infection, Per- \\ operative mortality and Epiplepsy.
}

\section{Extra cranial approach}

Indication: Posterior wall fracture that cannot be managed by endoscopy

Surgery

-Bicoronal scalp incision

-Frontal osteoplastic flap.

-MUCOSA that was disrupted, loose or folded was removed.

-Loose bony fragments of the posterior wall were repositioned and aligned to reestablish normal sinus anatomy..

-He nasofrontal duct was explored with a probe for patency in all patients

-The defect is identified and repaired directly using tissue grafts.

-Success rates with this approach range from $86 \%$ to $97 \%$

Complcation: Failure, wound infection.

patients, the leakage site was primarily from the posterior

frontal table, and the frontonasal pathway was intact.

\section{Cranialization of the frontal sinus:}

Indication: Severe communicated posterior wall fracture with CSF leak

Surgery:

-Bicoronal scalp incision

-Dissection of a pericranial flap and harvesting of split calvarial bone grafts when

Necessary

- Can be done through a frontal osteoplastic flap or frontal craniatomy.

- Removal of sinus mucosa

- Removal of posterior wall of frontal sinus

-Occlusion of nasofrontal recess.

- Dura repair by running suture or using graft

- Establishing a secure barrier between the cranial fossa and the nose is mandatory

to prevent CSF leak and meningitis, but also to prevent ascending regrowth of the sinonasal mucosa with late mucocele.

-Pericranial flap is sutured as far back as possible to the cranial base dura over the anterior cranial fossa to provide additional isolating layer of vascularized tissue Complication: Failure to stop leakage, Anosmia, Meningitis, Wound infection, Peroperative mortality and Epiplepsy 


\section{Conclusion}

Surgical management of Frontal sinus CSf leak should be done after careful assessment to the site of defect, size of defect, associated injuries (cranial, facial and orbital), nasofrontal duct situation, intracranial hypertension and in conjunction with neurosurgeons and maxillofacial surgeons. Endoscopy Surgical Management of Frontal sinus CSf leak still a challenge to surgeons and we and technologist may need to improve the endoscopic instruments using for frontal sinus Surgery.

\section{Acknowledgments}

None.

\section{Conflict of interest}

The author declares there is no conflict o interest.

\section{References}

1. Bhavana K, Kumar R, Keshri A, et al. Minimally Invasive Technique for Repairing CSF Leaks Due to Defects of Posterior Table of Frontal Sinus. J Neurol Surg B Skull Base. 2014;75(3):183-186.

2. Lee DH, Lim SC, Joo YE. Treatment outcomes of endoscopic repairs of sinonasal cerebrospinal fluid leaks. J Craniofac Surg. 2011;22(4):12661270 .

3. Nyquist GG, Anand VK, Mehra S, et al. Endoscopic endonasal repair of anterior skull base non-traumatic cerebrospinal fluid leaks, meningoceles, and encephaloceles. J Neurosurg. 2010;113(5):961-966.

4. Wu X, Wang Y, Yue J, et al. The key points to the successful repair of cerebrospinal fluid rhinorrhea]. Lin Chung Er Bi Yan Hou Tou Jing Wai Ke Za Zhi. 2014;28(9):618-620.

5. Virk JS, Elmiyeh B, Saleh HA. Endoscopic Management of Cerebrospinal Fluid Rhinorrhea: The Charing Cross Experience. J Neurol Surg B Skull Base. 2013;74(2):61-67.
6. Martín-Martín C, Martínez-Capoccioni G, Serramito-García R, et al. Surgical challenge: endoscopic repair of cerebrospinal fluid leak. $B M C$ Research Notes. 2012;5:459.

7. Roehm CE, Brown SM. Unilateral endoscopic approach for repair of frontal sinus cerebrospinal fluid leak. Skull Base. 2011;21(3):139-146.

8. Reyes C, Solares CA. Endoscopic Repair of Frontal Sinus Cerebrospinal Fluid Leaks after Firearm Injuries: Report of Two Cases. J Neurol Surg Rep. 2015;76(1):e8-e12.

9. Jones V, Virgin F, Riley K, Woodworth BA. Changing paradigms in frontal sinus cerebrospinal fluid leak repair. Int Forum Allergy Rhinol. 2012;2(3):227-232.

10. Archer JB, Sun H, Bonney PA, et al. Extensive traumatic anterior skull base fractures with cerebrospinal fluid leak: classification and repair techniques using combined vascularized tissue flaps. J Neurosurg. 2016;124(3):647-656

11. Shi JB, Chen FH, Fu QL, et al. Frontal sinus cerebrospinal fluid leaks: repair in 15 patients using an endoscopic surgical approach. ORL $J$ Otorhinolaryngol Relat Spec. 2010;72(1):56-62.

12. Becker SS, Duncavage JA, Russell PT. Endoscopic endonasal repair of difficult-to-access cerebrospinal fluid leaks of the frontal sinus. $\mathrm{Am} \mathrm{J}$ Rhinol Allergy. 2009;23(2):181-184.

13. Lee DH, Lim SC, Joo YE. Treatment outcomes of endoscopic repairs of sinonasal cerebrospinal fluid leaks. J Craniofac Surg. 2011;22(4):12661270.

14. Freeman JL, Winston KR. Breach of Posterior Wall of Frontal Sinus: Management with Preservation of the Sinus. World Neurosurg. 2015;83(6):1080-1089.

15. Chegini S, Gallighan N, Mcleod N, et al. Outcomes of treatment of fractures of the frontal sinus: review from a tertiary multispecialty craniofacial trauma service. Br J Oral Maxillofac Surg. 2016;54(7):801805.

16. Abuabara A. Cerebrospinal fluid rhinorrhoea: diagnosis and management. Med Oral Patol Oral Cir Bucal. 2007;12(5):E397-E400. 